\title{
O PROFESSOR DIRETOR DE TURMA COMO \\ MEDIADOR DO PROCESSO DE ENSINO-APRENDIZAGEM
}

\author{
Andrevaldo Glaidson Pereira Tavares ${ }^{1}$
}

Resumo: Atualmente nas escolas, percebe-se, mediante a indisciplina, um discurso por parte do responsável pela educação: "o que posso fazer?" Como alternativa eficiente, o Estado do Ceará implementou o Projeto Professor Diretor de Turma (PPDT), iniciado em Portugal, o qual tornou-se primordial para a educação qualitativa. Uma das cidades escolhidas para sediar esse projeto fora Barbalha, localizada no sul do estado, em que a economia gira em torno de um polo industrial crescente, com ênfase nos termoplásticos, nos minérios de calcário, nos fármacos e no beneficiamento e rapadura, sendo que a principal vocação da cidade ainda é a agropecuária, dentre todas as escolas estaduais a primeira a implantar o PPDT fora a Escola Estadual de Ensino Profissional Otília Correia Saraiva (EEEPOCS), criada aos 28 de julho de 2008, em que o projeto alavancou resultados inesperados nos últimos quatro anos; ao analisar o ambiente escolar é perceptível que o professor teve papel essencial nesse novo processo metodológico; tendo a família se aproximado da escola e ajudou a crescer; é visível também que o Diretor de Turma (DT) constitui uma ponte, um elo que entrelaça e aproxima o professor à família, o aluno à coordenação, o plano e a ação, o projeto e a realidade; garante que o planejamento seja individual, por área do conhecimento e valorize o projeto político pedagógico escolar, unindo forças ao Conselho Escolar e aos dirigentes administrativos, buscando pela qualidade do ensino ofertado, é fiscalizado dentre os docentes, em situações, 
pai/mãe dos discentes, comunga de justiça e trabalha baseado em atos, preceitos e legislação.

Palavras-chave: Diretor de Turma. Educação cearense. Sucesso escolar.

Abstract: Currently in schools, it is perceived by indiscipline, a speech by the person responsible for education: "what can I do?" How efficient alternative, the State of Ceará implemented the Project Officer Class Teacher (PPDT) started in Portugal, the which has become paramount to quality education. One of the cities chosen to host this project off Barbalha, located in the southern state where the economy revolves around a growing industrial center, with emphasis on thermoplastics in limestone ores, pharmaceuticals and processing and brown sugar, and the main vocation of the city is still agriculture, among all state schools the first to deploy PPDT outside the state School for Professional Teaching Otília Correia Saraiva (EEEPOCS), created to July 28,2008 , where the project leveraged unexpected results in last four years; when analyzing the school environment is noticeable that the teacher had key role in this new methodological process, taking the family approached the school and helped to grow, it is also apparent that the Director Class (DT) is a bridge, a link that intertwines and approaching the teacher to the family, the student coordinating the action plan and the design and reality; ensures that planning is individual, by knowledge area and enhances the political pedagogical project school, joining forces with the School Board and administrative officers, looking for the quality of education offered, among teachers is supervised, in situations, father/ mother of learners, shares of justice and works based on acts, ordinances and laws.

Keywords: Officer Class. Education in Ceará. School success. 


\section{Introdução}

Oriundo de Portugal, e adaptado para o Brasil pela professora Haidé Eunice Gonçalves Ferreira Leite, o Projeto Professor Diretor de Turma (PPDT) surge como uma alternativa de gestão pedagógico-administrativa para interligar a escola à família. Em antecedência à sua implantação, com três escolas-piloto em 2008 e ampliação para cem em 2010, o projeto veio para erradicar uma questão popular dentre o quadro pedagógico da educação brasileira: qual é o real papel da família e da escola na educação de uma criança?

Numa tentativa de resposta, Oliveira (1993) afirma que "uma das funções principais da família é a educação", é na família que a criança aprende valores e padrões culturais da sociedade.

Em contrapartida, Machado (1975) afirma que “[...] embora a família se incumbisse outrora da educação [...] há necessidade de uma determinada atividade que reúna requisitos de certa complexidade que é a educação formal." Nesse contexto, a escola fez sua aparição no meio social, ela é assim, por excelência, a agência encarregada da educação formal dos indivíduos.

Essa controvérsia de opiniões provocou ao passar dos anos uma distância entre a família e o ambiente escolar. No entanto, como consequência, surge a indisciplina como problema sério no que refere-se a convivência, perturbando o real papel do professor junto ao processo de ensino-aprendizagem.

Quando consultados, mediante a indisciplina de um educando, percebe-se uma fala por parte do responsável pela educação: “o que posso fazer?” O que eleva o fato do pensar de muitos educadores que a escola não passa de um ambiente onde a família literal- 
mente "descarrega um fardo", visão essa que agrava cada vez mais a relação família-escola.

Zenhas (2006) enfatiza que falar de colaboração entre escola e família pode levar a diversas questões; a primeira delas é quê a definição de papéis e funções entre a escola e a família não são claras nem consensuais; a segunda refere-se ao que tipo de colaboração se pretende da família no ambiente escolar ou da escola no ambiente familiar.

Outro fato que agrava a inteiração escola-família se dá no Nordeste brasileiro, onde ou os filhos superam a escolaridade dos pais, ou as famílias são grupos sociais complexos repletos de indivíduos, numerosas, que não atende a exigência única de um educando. Fatos esses que confundem a ideologia da doutrina educacional e cria um paradoxo entre a educação formal e informal.

\section{Educação formal versus educação informal}

\section{Educação formal}

Como o próprio nome indica, o processo formal baseia-se em normativas, padronizações analisadas e preestabelecidas em forma de constituição, que regem um padrão, modelo ou guia descrito por especialistas em educação. Saviani et al. (2006) descrevem como sendo um "[...] processo de educação realizado em um sistema escolar de ensino, podendo ser desenvolvido em institutos e demais instituições legitimadas para exercê-la."

Esse processo realiza-se em unidades especiais, ou simplesmente unidades de ensino, que fazem uso de um corpo acadêmi- 
co graduado com formação específica por área do conhecimento e modalidade educacional - disciplina.

\section{Educação informal}

Por ela a criança/educando cria saberes sociais, tabus, paradigmas, ideologias, preceitos e conceitos em eixo hereditário. Surge durante a educação informal o conhecimento de mundo, a formação da personalidade, a postura e a conduta em ambiente familiar e nas ruas. Brandão (1985) define essa metodologia como sendo um “[...] processo livre, não-institucionalizado, de transmissão de certos saberes, tais como: a fala comum a um dado grupo, as tradições culturais e demais comportamentos característicos das diversas comunidades presentes em uma sociedade."

\section{Relação existente entre educação formal e informal}

Gaspar (2002) aproximou essas duas modalidades educacionais quando as correlacionou dizendo que

[...] a aprendizagem de um novo conceito é um processo de desenvolvimento cognitivo longo, cuja construção apenas começa na ocasião em que o aluno é ensinado. Essa construção, por sua vez, se assenta na estrutura cognitiva que o aprendiz desenvolveu até esse momento, num processo contínuo iniciado desde os seus primeiros dias de vida, sucedido até sua plena inserção na sociedade.

Percebe-se facilmente a importância do conhecimento de papéis e/ou funções claras entre o representante legal do aluno e o 
educador da escola formal, uma vez que o objetivo conjunto está na formação socioeducacional cognitiva e cívica do educando.

Nesse eixo, a escola tem papel de promotor dos conceitos sólidos, padronizados e que garante a inclusão social, a educação para o trabalho, o protagonismo e o instinto de corresponsabilidade, o que, visivelmente, percebe-se a concepção de líderes.

Porém esse perfil resguarda um ser que traz consigo uma história prévia que não deve ser desvalorizada, nem desprezada no contexto escolar, o que deve ser essencial para o sucesso no processo de ensino-aprendizagem: o aperfeiçoamento do saber prévio e sua moldura em suporte técnico, o que garantirá o bom desempenho no durante a fase das responsabilidades próprias - fase adulta.

\section{Estudo de caso: o professor diretor da turma}

Uma alternativa de gestão pedagógico-administrativa para interligar a escola à família, alinhando-os em meta durante o processo educacional, surgiu em 2007, com o Projeto Professor Diretor de Turma (PDDT), implantado na rede pública estadual do Estado do Ceará, desde o momento que a professora portuguesa, Haidé Eunice Gonçalves Ferreira Leite, inspirada nas propostas pedagógicas de nossa matriz linguística firmada em Portugal, explanou sobre um novo modelo educacional no XVIII Encontro Estadual do Ceará, o que provocou curiosidade dentre os gestores escolares que ali se faziam presentes.

A consequência direta fora a adesão de três unidades de ensino do estado que passaram a adotá-lo, duas escolas municipais e uma estadual, nos municípios de Eusébio, Madalena e Canindé. 
Segundo a professora Haidé, os primeiros resultados constatados se constituíram matéria divulgada no XXIII Simpósio Brasileiro de Política e Administração da Educação, em 2007, em Porto Alegre, onde os gestores da Secretaria de Educação do Estado (SEDUC/CE) ficaram sabedores dos indícios de sucesso da nova função implantada e, em parceria com a Associação Nacional de Política e Administração da Educação (ANPAE/CE), assumiram o desafio de implantar o projeto do Professor Diretor de Turma até o ano de $2010 \mathrm{em}$ cem escolas integradas do ensino médio profissionalizante.

Outra consequência importante acerca da implantação pode-se verificar em uma decrescência nos índices de abandono escolar, uma vez que uma das funções do Diretor de Turma está em verificar semanalmente as faltas dos alunos nas diferentes disciplinas, relevar as devidamente justificadas e informar, por escrito, os encarregados de educação sempre que o número de faltas dos respectivos educandos atinja metade ou o total do limite legalmente estabelecido, elucidando-os das consequências caso esse limite seja ultrapassado.

Um fato interessante aconteceu com a efetiva participação da família acerca da formação do aluno da escola pública, o que anteriormente era uma exclusividade da rede de ensino privada, no Brasil, essa contribuição fortalece a confiança dos educadores.

\section{O professor diretor de turma}

Segundo o regimento interno do projeto, o Diretor de Turma (DT) deve ser um professor que leciona disciplina de sua área de formação e simultaneamente a disciplina de formação para a cidadania (F.C.). 
Suas atribuições vão de encontro à articulação entre pais, núcleo gestor, professores e alunos que compõem a turma.

Segundo a professora Haidé, a finalidade das ações do DT é promover valores intrínsecos à aprendizagem mediante convivência solidária e social em que os atores são, também, espectadores; as intervenções são delineadas em reunião do conselho de turma e registradas em ata. Assim sendo, o núcleo gestor tem conhecimento do que se passa na turma, apoiando ou resolvendo as questões inerentes aos alunos.

Fundamentando-se a matriz do projeto em Portugal, o DT tem por competências e deveres:

- esclarecer os alunos acerca das funções do diretor de turma e informá-los, assim como aos encarregados de educação, do seu horário de atendimento;

- estimular a participação do aluno na vida da escola e da comunidade;

- promover a eleição do delegado e subdelegado de turma e fornecer o nome destes ao núcleo gestor, a fim de ser elaborado o caderno para a eleição dos representantes dos alunos junto ao conselho pedagógico;

- criar e desenvolver um diálogo aberto com a turma;

- facilitar aos encarregados de educação a comunicação com a escola, mantendo-os informados e esclarecidos, quer por meio de reuniões, quer por intermédio de correspondência e dos contatos semanais;

- organizar e garantir a funcionalidade do dossiê de turma;

- verificar semanalmente as faltas dos alunos nas diferentes disciplinas, relevar as devidamente justificadas e informar, por escrito, os encarregados de educação sempre que o número de faltas dos respectivos educandos atinja metade ou o total do limite legal- 
mente estabelecido, elucidando-os das consequências caso esse limite seja ultrapassado;

- estar atento às informações dadas pelos professores e comunicá-las aos encarregados de educação, sempre que a situação do aluno o aconselhar; exigir aos professores da turma que comuniquem, sempre e por escrito, as infracções disciplinares cometidas pelos alunos que impliquem falta de presença;

- verificar o registro das datas de marcação das fichas de avaliação somativa, de forma a que não seja marcada mais do que uma prova de avaliação no mesmo dia;

- presidir às reuniões de conselho de turma, que deverão ser previamente preparadas;

- apresentar ao núcleo gestor um relatório crítico anual do trabalho desenvolvido;

- garantir uma informação atualizada e esclarecer os alunos acerca da assiduidade, pontualidade, regime de faltas, regras internas da escola, disciplina e regras de procedimento disciplinar, importância e funções do delegado e subdelegado de turma, avaliação e orientação escolar.

Implantação do projeto professor diretor de turma (PPTDT) em Barbalha (CE)

A região do Cariri é composta por 32 municípios da região sul do estado do Ceará. Barbalha é um dos que fazem parte da região metropolitana, e nela percebe-se um destaque especial no turismo, por sua privilegiada situação ao sopé da floresta nacional do Araripe. A cidade possui 54.806 habitantes (IBGE, 2010); conhecida nacionalmente como o celeiro cultural do Cariri, destaca-se por seu 
grande número de grupos folclóricos, mestres da cultura e pela riqueza de sua história como patrimônio cultural e imaterial. Em décadas passadas já teve sua história de sucesso econômico com a produção de cerâmica e açúcar. Atualmente, a economia gira em torno de um polo industrial crescente, com ênfase nos termoplásticos, nos minérios de calcário, nos fármacos, no beneficiamento e rapadura, sendo que sua vocação ainda é a agropecuária. Nela situa-se a sede da Escola Estadual de Ensino Profissional Otília Correia Saraiva (EEEPOCS), criada aos 28 de julho de 2008.

Com a missão de ofertar ensino médio integral e integrado à educação profissional, oferecendo ensino de qualidade, formando jovens autônomos, solidários, éticos, aptos pelo empreendedorismo, pela continuidade dos estudos e pela inserção no mundo do trabalho. (ESCOLA..., 2012).

Focada nessa missão, a escola assenta-se sobre as premissas do protagonismo juvenil, ensino por competências, pedagogia da presença, construção do projeto de vida e utilização dos quatro pilares da educação permeiam nossa prática diária nas formas de ver e cuidar da juventude, trabalhando para ampla formação dos jovens e o que contribui em melhorias na qualidade de vida. Como toda unidade de ensino futurista, baseada em um histórico de excelência em desenvolvimento de projetos pedagógicos, formação de profissionais que abastecem o mercado de trabalho local e de jovens que visam continuação de seus estudos, a escola desenvolve-se sobre uma meta operacional.

Sua visão é ter reconhecido local, regional e nacional como uma instituição de referência em ensino médio integrado à educação profissional pela excelência no ensino e na formação de jovens Protagonista e empreendedores. (ESCOLA..., 2012). 
Inicialmente, agosto de 2008, a escola atendeu a 180 alunos, oriundos do município sede, distribuídos nos cursos técnicos de Enfermagem (uma turma), Segurança no trabalho (uma turma) e Informática (duas turmas). Atualmente, a escola atende aos municípios de Barbalha, Missão Velha e Juazeiro do Norte, com assistência a integral a 360 alunos distribuídos nos cursos técnicos de Enfermagem (três turmas), Nutrição (duas turma), Informática (duas turmas) e Redes e Manutenção de Computadores (duas turmas).

\section{O projeto diretor de turma na Escola Estadual de Educação Profissional Otília Correia Saraiva, de Barbalha (CE)}

Como marco fundamental da aprendizagem, a escola conta com nove professores diretores de turma e uma coordenadora da área, que atuam em âmbito de assistencialismo ao estudante, acompanhando seu desenvolvimento sócio afetivo, profissional, cognitivo, cultural e cívico. Suas funções vão desde o registro de ocorrências até o acompanhamento de infrequência, sendo ele o elo entre a escola e a família.

É função do DT ministrar reuniões de responsáveis pela educação e atendê-los em regime individual. São eles quem garantem a boa conduta e servem de exemplo moral para a concepção cívica. Atuam também como interlocutores que de forma efetiva resolvem questões de convívio seja entre aluno-aluno, aluno-professor e/ou aluno-gestor.

Outra ação direta é a presidência do conselho de sala e da Reunião Intercalar, em que caracterizam os alunos em sua peculiar necessidade, para que possam ser compreendidos pelos membros 
do conselho, os quais deliberam sobre metas e metodologias aplicáveis para elevação dos índices de atuação, participação, desempenho e aprendizagem dos alunos da turma.

O Diretor de Turma é, antes de mais, um educador; ele é o professor que acompanha, apoia e coordena os processos de aprendizagem, de orientação, de maturação dos alunos e de orientação e de comunicação entre os docentes, alunos, pais/encarregados de educação e restantes agentes da ação educativa.

O DT assume-se com o papel de "tutor", no sentido de protetor, conselheiro, regulador/estabilizador e orientador do desenvolvimento pessoal e intelectual do aluno, definindo-se como um professor que conhece bem os seus alunos, que coordena e lidera uma equipe pedagógica, que aproxima todos os elementos dessa equipe e que estimula e monitoriza a concepção e a realização de projetos e das atividades que estes projetos envolvem. Ele é o elo entre escola-aluno, escola-pais, alunos-escola.

Principais ações de um diretor de turma

As ações diretas dos professores que se enquadram nesse perfil estão relacionadas a:

1) Construção do Dossiê de Turma, instrumento este no qual estão narradas em fichas próprias do projeto e adaptadas a cada público, a vida escolar, a situação familiar, a ações de sucesso ou falha, a rendimento e infrequência, caracteres peculiares que podem vir a influir no desempenho e o acompanhamento específico de cada aluno. Ele serve como norte, por meio dele um leitor pode interpretar e compreender a turma em diferentes lugares e situa- 
ções. Outrora serve de registro/documento, o que implica "prova" concreta de momentos difíceis ou de metodologias que impulsionaram a evolução da turma.

2) Atendimento ao responsável pela educação, em momento específico, predestinado ou sempre que necessário, na busca incansável pela aproximação da família da formação formal do educando. Por este momento o DT conhece a realidade do ambiente que circunda o aluno fora da escola, e por ele conhece com autoridade os melhores passos que cada educador deve dar para conseguir melhoria de resultados.

3) Atendimento ao aluno, como indivíduo que precisa, antes de mais nada, de atenção, afinal, sem aluno não há escola! Ele é o protagonista do processo e merece atenção em suas peculiaridades. Nesse momento, o DT conquista a confiança e a partir daí poderá proceder ajustes no processo educacional.

4) A aula de Formação para Cidadania, componente curricular, que foca a formação de líderes. Esse momento dinâmico abrange temáticas sociais que se ajustam ao momento do aluno. O planejamento procede-se com flexibilidade e atende, além de questões de moral, de ética e de cidadania, temas como a puberdade ou situações problemas de cada faixa etária.

Visões acerca dos diretores de turma

\section{Pelos gestores}

O Diretor de Turma é o elemento do grupo que cria o ambiente para que os alunos possam partilhar as suas experiências, preocu- 
pações, fobias, permitindo-lhes exprimirem-se de modo aberto e objetivo, sendo um verdadeiro amigo/conselheiro e um tutor que se empenha no sucesso dos seus alunos.

Ele é o professor que acompanha, apoia e coordena os processos de aprendizagem, desenvolvimento e orientação entre alunos, professores e encarregados de educação.

Cabe ao DT estabelecer a ligação entre os diversos intervenientes na relação educativa e funciona como suporte de coordenação de equipes de trabalho, que planifica a concepção de projetos e estratégias, distribui informação e articula a realização de atividades.

No enquanto, como líder da turma, o DT não deixa de manter a ordem e o controle desta, pedindo responsabilidades e distribuindo tarefas, quer aos alunos, quer ao conselho de turma para guiar a todos focando-os no seu objetivo final - o sucesso escolar do seu grupo turma, por intermédio de uma adequada gestão curricular. Nesta linha de pensamento de que o DT deve possuir um perfil adequado de líder eficaz, o papel do diretor de turma é também relevante na gestão das próprias relações, dependendo muito da sua estratégia como líder a eficácia do funcionamento deste órgão.

O DT deve saber gerir a sua própria imagem, pois o reconhecimento pelos alunos e entre os seus pais pode ter um impacto inestimável na consecução de um trabalho, bem como fomentar um espírito de equipe. Em síntese, o DT deve ser dialogante/comunicativo, aberto, justo, compreensivo, tolerante, firme, disponível, dinâmico e com método, responsável, criativo, competente, maduro, coerente, decidido; deve saber prever e resolver situações, solucionar problemas, gerir os conflitos, promover o trabalho de 
equipe, ponderado e equilibrado; enfim, ser um verdadeiro líder democrático e responsável.

Deve ainda possuir as competências que caracterizam profissionalmente qualquer docente: ser pedagogicamente um bom profissional, ter conhecimentos aprofundados e atualizados acerca do que leciona e saber transmiti-los de uma forma adequada, promover um bom relacionamento com os alunos, desenvolver, com estes, o trabalho em equipe; ser autônomo na utilização das novas tecnologias, considerando-as como mais uma estratégia, para variar e inovar as suas práticas pedagógicas; saber trabalhar em equipe com os seus colegas; saber aplicar a interdisciplinaridade. Também sabemos que não é fácil que todo e qualquer professor possua na íntegra esta lista tão alargada de qualidades. Porém, é importante que o professor indicado para o cargo de DT seja aquele que mais atributos usufruam, não prescindindo o de saber gerir e aplicar a gestão flexível do currículo.

\section{Pelos educadores}

No que diz respeito aos educadores, é falho pensar que o Professor Diretor de Turma é um e o único regente supremo. É visível a descentralização da hierarquia escolar e o foco em um único personagem, protagonista na solução de situações problemáticas. Alguns esquecem que nos momentos de aula o DT torna-se mais um professor que soma esforços para o sucesso da turma. São muitas as situações em que educadores e DTs devem interagir, no entanto, um dos papéis essenciais do PDT é a elaboração de um Dossiê de Turma, no qual registra situações, eventos, fichas esclarecedo- 
ras acerca da vida e do desenvolvimento estudantil dos alunos. $\mathrm{O}$ que ainda falta é que os educadores entendam que o Dossiê não é um instrumento de gaveta, que ele é resposta para situações particulares, que nele há espaço para registros individuais e coletivos, sejam de problemas, sejam dde propostas de soluções; que seja a resposta que os professores querem sobre o desenvolvimento da sala e/ou de um aluno em específico encontra-se narrado previamente em um dos instrumentos construídos pelo DT.

\section{Pelos educandos}

Aos alunos a pesquisa proposta levantava questões sobre a primeira visão dos Professores Diretores de Turma, seu relacionamento, sua relevância em sua formação, sua ação e inter-relação. Foram entrevistados 65 alunos, distribuídos cinco por turma/curso; dentre esse público estiveram atuais educandos e técnicos de formação concluída. Dentre as respostas analisadas, as que mais chamaram atenção foram as citadas abaixo.

Segundo Ian Vieira ${ }^{2}$, inicialmente o PPDT foi proposto aos alunos, sendo exposto o objetivo e todo o planejamento do projeto, com diversas avaliações durante a implantação, tendo resultado positivo durante esse período. Por ser "algo" novo, houve resistência dos alunos, mas rapidamente aconteceu a adaptação. No começo achavam que não daria certo, no entanto após conversas, atendimentos realizados, o diretor de turma tornou-se o líder, modelo e exemplo para nós. Seus primeiros passos de interação mediavam-se por debater acerca dos problemas e as dificuldades que a classe apresentava onde buscavam soluções conjuntas de 
forma a beneficiar todos. Os primeiros problemas, ou melhor, dificuldades centravam-se no teor da hierarquia, pois alguns poucos não aceitavam a autoridade do Diretor de Turma, havia questionamentos sobre sua verdadeira função. Com o passar dos dias, e em ação conjunta do Diretor, podemos enxergar nosso professor como a pessoa mais próxima a nós dentre todos que componham a escola. Somente a partir daí começamos a confiar nossos anseios e angústias, fossem elas escolares ou pessoais, e em ação vinham os conselhos, atrelando-se um laço afetivo o que nos aproximou o ambiente escolar do ambiente familiar. Com isso encontramos no nosso professor mais que um simples educador, um amigo e, sendo mais ousado, um "pai".

Na visão da aluna Thalita ${ }^{3}$, o Projeto Professor de Turma apresenta um nível de extrema relevância, sendo de suma importância pelo fato de os diretores estarem sempre buscando o melhor para seus alunos, auxiliando-os da melhor maneira possível, de forma bastante direta. Creio que a única falha do projeto seja o fato de os alunos não escolherem seu diretor, mas em compensação tudo que eles fazem é necessário para que o aluno tenha um bom rendimento escolar e familiar. O DT é essencial, pois está sempre ao lado do aluno lhe ajudando. Como ponto forte o DT deve acima de qualquer coisa sempre compreender sua turma, ser companheiro, procurando estar presente e ciente de todos os defeitos e qualidades dos alunos. No convívio afetivo familiar, o DT atua como ponte, com essa interação nossos familiares sempre poderão saber o que acontece com nós, até porque sem essa ponte tudo seria mais difícil no cotidiano, afinal nós estudantes passamos praticamente o dia inteiro na escola, sem o contato direto com nossos pais. No que diz respeito a sua ação para conosco, ele nos ajuda bastante, 
procurando sempre inovações que melhorem nosso convívio e pensando sempre em algo que possa nos favorecer na formatura, para nós ele se tornou o nosso maior companheiro dentro da escola, vai ser ele quem irá nos acompanhar em tudo que acontecer nesses três anos de formação.

\section{Pelos responsáveis pela educação}

Para os pais/responsáveis, o PDT representa o acesso a vida, a formação, a confiança do jovem. No DT os pais depositam sua confiança, sabendo eles que na escola seus filhos estão bem "guardados", protegidos, amparados. Os pais entendem que os PDT são professores, que têm funções especiais e que melhor representam seus filhos durante sua formação acadêmica. O modelo, o exemplo, a inspiração, o que justifica o fato da presença dos pais junto aos eventos escolares, aos momentos de superação e ao acompanhamento do desempenho escolar. Alguns pais descrevem os DTs como seus representantes/porta-voz na escola, entendendo eles que é sua função primordial prezar pelo bem-estar e pelo sucesso do aluno seja na vida pessoal, seja no desenvolvimento acadêmico profissional.

\section{Considerações finais}

A presente pesquisa propôs uma análise crítica sobre o papel da família e da escola durante o processo educacional. Durante seu desfecho, pode-se constatar que o processo histórico distan- 
ciou aos poucos a educação formal (escola) da educação informal (família).

Numa tentativa de busca por melhores resultados e principalmente para resgatar a participação da família no convívio escolar o Governo do Estado do Ceará lançou em 2008 o Projeto Professor Diretor de Turma, uma adaptação de sua matriz portuguesa, que após sua implantação tornou-se um ponto primordial na educação qualitativa.

Na Escola Estadual de Educação Profissional Otília Correia Saraiva, de Barbalha (CE), alvo desta pesquisa, o projeto alavancou resultados inesperados nos últimos quatro anos; a escola partiu de uma unidade educacional recém-fundada a um modelo qualitativo reconhecido no estado e premiado nacionalmente.

O Professor Diretor de Turma teve papel essencial nesse alavancar sociocultural; por ele a família aproximou-se da escola e a ajudou a crescer. A aceitação dos DTs se faz de forma positiva junto aos alunos e suas intervenções estão narradas com os índices de evasão, repetência e infrequência zerados nos quatro últimos anos.

Outro fato interessante está na inexistência da recuperação anual, uma vez que o Diretor de Turma acompanha a infrequência e a evolução de situações problemas resolvendo-as de forma efetiva e mediata.

No que condiz ao relacionamento, percebe-se que tanto professores quanto DTs correlacionam e comungam da mesma meta o sucesso de cada um que compõe a turma. O PDT constitui uma ponte, um elo que entrelaça e aproxima o professor à família, o aluno à coordenação, o plano e a ação, o projeto e a realidade.

O DT, além de orientador, é um vocacional, garantindo que o planejamento, seja individual, seja por área do conhecimento, 
valorize o projeto político pedagógico escolar. Ele une forças ao Conselho Escolar e aos dirigentes administrativos na busca pela qualidade do ensino ofertado. Ele é fiscal dentre os docentes, em situações, pai/mãe dos discentes, comunga de justiça e trabalha baseado em atos, preceitos e legislação.

\section{Referências}

BRANDÃO, C. Casa de escola: cultura camponesa e educação rural. Campinas: Papirus, 1985.

BRASIL. DECRETO No 5.154 DE 23 DE JULHO DE 2004. Diretrizes para a Educação Profissional. 2004. Disponível em: <http://www. planalto.gov.br/ccivil_03/_ato2004-2006/2004/decreto/d5154.htm>.

. LEI No 9.394 DE 20 DE DEZEMBRO DE 2006. Lei de Diretrizes

e Bases da Educação. 2006. Disponível em: <http://www.planalto.gov. br/ccivil_03/leis/L9394.htm>.

LEI No 11.892 DE 29 DE DEZEMBRO DE 2008. Lei de Diretrizes da Educação Profissional. 2008. Disponível em: <http:// www.planalto.gov.br/ccivil_03/_ato2007-2010/2008/lei/111892.htm>.

ESCOLA Estadual de Educação Profissional Otília Correia Saraiva. Projeto Político Pedagógico - PPP EEEPOCS. Barbalha, [20--].

GASPAR, A. A educação formal e a educação informal em ciências. Ciência e Público - caminhos da divulgação científica no Brasil. Rio de Janeiro: Casa da Ciência; UFRJ, 2002.

IBGE. Censo 2010. Brasília: IBGE, 2010. Disponível em: <http://www. censo2010.ibge.gov.br/dados_divulgados/index.php?uf=23>.

LEITE, H. E. G. F.; CHAVES, M. L. B. O Projeto Diretor de turma no ceará, dois anos depois. [20--]. Disponível em: $<$ http:// diretordeturma18.blogspot.com/2011/06/o-projeto-diretor-de-turmano-ceara.html>. 
MACHADO, A. L. N. Sociologia Básica. São Paulo: Saraiva, 1975.

OLIVEIRA, P. S. Introdução à sociologia da educação. São Paulo: Ática, 1993.

SÁ, V. Racionalidades e práticas da gestão pedagógica: o caso do diretor de turma. Lisboa: Instituto de Inovação Educacional, 1997.

SAVIANI, D.; ALMEIDA, J. S.; SOUZA, R. F.; VALDEMARIN, V. T. O legado educacional do século XIX. Campinas: Autores Associados, 2006.

ZENHAS, A. O papel do diretor de turma na colaboração escolafamília. Portugal: Porto, 2006.

Tudo sobre Diretor de turma. [20--]. Disponível em: <http:// dtnet.no.sapo.pt/index2.htm>.

\section{Notas}

${ }^{1}$ Graduado em Tecnologia de Alimentos pelo Instituto Centro de Ensino Tecnológico (CENTEC), especialista em Biologia e Química pela Universidade Regional do Carirí (URCA).

${ }^{2}$ Ian Vieira Silva - técnico em Segurança do Trabalho. Ex-aluno da I Turma de Segurança do Trabalho da Escola Estadual de Educação Profissional Otília Correia Saraiva (EEEPOCS). 2008-2010.

${ }^{3}$ Thalita Aparecida Duarte Vieira - técnica em Nutrição. Aluna da I Turma de Nutrição da Escola Estadual de Educação Profissional Otília Correia Saraiva (EEEPOCS). 2011-2013. 
